\title{
Electrocardiographic Abnormalities in the Elderly: A Study in a Large Database of Primary Care Patients
}

\author{
Marcolino $\mathrm{MS}^{* 1,2}$, Cury $\mathrm{GA}^{2}$, and Ribeiro $\mathrm{AL}^{1,2}$ \\ ${ }^{1}$ Department of Internal Medicine, Universidade Federal de Minas Gerais, Belo Horizonte, Brazil \\ ${ }^{2}$ Telehealth Center, University Hospital, Universidade Federal de Minas Gerais, Belo Horizonte, Brazil
}

${ }^{*}$ Corresponding author: Marcolino MS, Department of Internal Medicine, Universidade Federal de Minas Gerais, Avenida Professor Alfredo Balena, 190 sala 246, Cep: 30130-100, Belo Horizonte, Brazil, Tel: 55-3134099201, E-mail: milenamarc@gmail.com

Citation: Marcolino MS, Cury GA, Ribeiro AL (2017) Electrocardiographic Abnormalities in the Elderly: A Study in a Large Database of Primary Care Patients. J Clin Exp Res Cardiol 3(2): 204

Received Date: August 11, 2017 Accepted Date: October 6, 2017 Published Date: October 09, 2017

\begin{abstract}
Introduction and objectives: Ageing is associated with increasing prevalence of chronic and degenerative disease and changes in cardiovascular structure, which may be associated with electrocardiographic abnormalities. Our aim is to assess the prevalence of electrocardiographic abnormalities in elderly primary care patients.

Methods: This retrospective observational study assessed all consecutive digital 12-lead electrocardiograms (ECGs) performed in 2011 by a public telemedicine service in Brazil. In that time, the service attended primary care of 658 cities in Minas Gerais province. The prevalence and type of ECG abnormalities in elderly patients ( $\geq 60$ years-old) was assessed.

Results: 87,804 elderly patients underwent ECG recording (median age 70 years; 57\% women). Hypertension was reported in $48.7 \%$, diabetes in $9.1 \%$, smoking in $6.4 \%$ and Chagas disease (ChD) in 3.5\%. Only $41.6 \%$ of patients had no ECG abnormality. The variables with the strongest association with abnormal electrocardiogram were $\mathrm{ChD}$ and previous myocardial infarction (MI) had. Atrial fibrillation was observed in $4.2 \%$; left bundle branch block in 3.6\%; right bundle branch block in 5.5\%; left ventricular hypertrophy in $6.2 \%$ and nonspecific repolarization abnormalities in $30.4 \%$. Chest pain was mentioned by $73.2 \%$ of the patients. Of these, $6.3 \%$ had abnormalities related to electric inactivity (poor R wave progression and pathological Q waves) and $2.1 \%$ abnormalities related to acute ischemia (ST elevation and ST depression).

Conclusion: This study showed that electrocardiographic abnormalities are common in elderly primary care patients, with a prevalence which increases with ageing. ChD and previous MI were the variables with stronger association with abnormal ECG.
\end{abstract}

Keywords: Elderly; Primary care; Electrocardiogram; Cardiovascular diseases

\section{Introduction}

Population ageing is a global phenomenon which increases the prevalence of chronic diseases and brings a big challenge to health policy planners. Cardiovascular diseases (CVD) are currently the main cause of mortality and morbidity worldwide [1]. In 2008, 17.3 million (30\%) of all global deaths were due to CVD, and this number is estimated to reach 23.3 million by 2030 [1,2]. Based on this scenario, healthcare systems from all nations have to adapt their policies to attend this new profile of patients and associated diseases. The majority of CVD can be prevented, thus it is important for healthcare systems worldwide to focus on the development of actions to minimize the incidence and the impact of the morbidity and mortality associated with CVD in advanced age [3].

The 12-lead electrocardiogram (ECG) is the most readily available noninvasive test for the detection of cardiac disease in primary care. It is a low-cost and very useful tool to assess the impact of CVD in the population context and to guide preventive actions. Relatively few epidemiological studies have been performed to assess the prevalence of electrocardiographic abnormalities in the elderly, and some ECG abnormalities have prognostic impact [4]. Therefore, the determination of the prevalence of electrocardiographic abnormalities in the elderly is of major clinical and epidemiological importance. The objective of this study was to analyze the prevalence and type of electrocardiographic abnormalities in elderly patients in primary care and their association with comorbidities and demographic variables. 


\section{Methods}

This retrospective observational study included all consecutive 12-lead digital ECGs analyzed by the cardiologists of the Telehealth Network of Minas Gerais, a public Brazilian telehealth service, from January $1^{\text {st }}$ to December $31^{\text {st }}$, 2011. In that time, the service provided support to primary care professionals of 658 cities in the state of Minas Gerais, 85\% of them with less than 14,000 inhabitants, by performing teleconsultation (defined as "synchronous or asynchronous consultation using information and communication technology to omit geographical and functional distance"[5]), and telediagnosis (remote analysis of exams), including ECG analysis [6].

The digital ECGs were recorded by nursing technicians from the family health program of the participating municipalities using a tele-electrocardiograph by Tecnologia Eletrônica Brasileira (TEB) or Micromed Biotecnologia and sent through the internet to the analysis center, where the exams were immediately directed to a team of cardiologists, trained and experienced in analysis and interpretation ECG using standardized criteria [7]. For the purpose of this study, elderly were defined by persons with age equal or higher 60 years-old. They were compared with people up to 59 years-old. Clinical data (age, sex, comorbidities) were selfreported, collected using a standardized questionnaire. Comorbidities included in the questionnaire were hypertension, diabetes, obesity, hyperlipidemia, chronic kidney disease, chronic obstructive pulmonary disease and Chagas disease (ChD). Smoking, family history of coronary disease and previous myocardial infarction were also included. All these variables were the same ones already used by the standard questionnaire of the ECG analysis used by the public telehealth service quoted. All consecutive exams performed in elderly patients were analyzed. ECGs with technical problems, as interference or lead placement errors, were excluded. The prevalence and type of electrocardiographic abnormalities were assessed and stratified by hypertension. The proportion of atrial flutter was considered with the proportion of atrial fibrillation (AF), as other epidemiological studies [8].

IBM SPSS Statistics for Windows version 20.0 (IBM Corp. Released 2011. Armonk, NY: IBM Corp) was used for statistical analysis. Categorical data were reported as counts and percentages; continuous variables were reported as mean and standard deviation (SD) or median (interquartile range [IQR]: $25^{\text {th }}$ and $75^{\text {th }}$ percentiles), as appropriate. To assess the association between abnormal ECG and clinical characteristics, univariate and multivariate odds ratios were estimated by logistic regression. Multivariate model included all clinical characteristics. A two-tailed p-value of 0.05 was considered statistically significant.

This study was approved by the Research Ethics Committee of the Universidade Federal de Minas Gerais.

\section{Results}

Thoughout the study, 264,324 exams were performed, $33.2 \%(87,804)$ of them were in elderly patients. The median population of the cities where these elderly were located was 8,924 inhabitants (IQR 5,213-14,592). The elderly group comprised 50,136 women (57.1\%). The median age was 70 years (IQR 64-76 years; maximum 105 years); 13,277 (15.1\%) were octogenarians and 1,575 (1.8\%) nonagenarians. For the non-elderly group, the median age was 43 (IQR 31-52) years and 60.9\% were women. Clinical characteristics of the elderly group are shown on Table 1.

\begin{tabular}{|c|c|}
\hline Variable & $\mathbf{N}(\%)$ \\
\hline Current smokers & $5,608(6.4)$ \\
\hline Hypertension & $42,752(48.7)$ \\
\hline Diabetes & $7,957(9.1)$ \\
\hline Dyslipidemia & $3,700(4.2)$ \\
\hline Chronickidneydisease & $451(0.5)$ \\
\hline Chagas disease & $3,114(3.5)$ \\
\hline COPD & $881(1.0)$ \\
\hline Previous MI & $1,007(1.1)$ \\
\hline Family history of CAD & $12,958(14.8)$ \\
\hline
\end{tabular}

List of Abbrevations: CAD: Coronary Artery Disease; COPD: Chronic Obstructive Pulmonary Disease; MI: Myocardial Infarction Table 1: Clinical characteristic of the elderly patients $(\mathrm{N}=87,804)$

Regarding the ECGs analysis, $41.6 \%$ of the ECGs had no abnormalities, vs. $69.6 \%$ in patients less than 60 years (p<0.001). Among patients who had abnormal ECG, it was frequent to have more than one abnormality. The association between abnormal ECG and clinical characteristics is shown on Table 2. The prevalence of normal ECGs decreased with ageing: 48.5\% in patients with 60-69 years of age, $37.7 \%$ in patients with $70-79$ years of age, $27.7 \%$ in patients with $80-89$ years of age and $23.3 \%$ in nonagenarians. In patients who had abnormalities, the median number of ECG abnormalities was 2 (IQR 1-2, maximum number of 10). The most frequent electrocardiographic abnormalities are shown in Table 3, for all patients and stratified by the presence of hypertension. 


\begin{tabular}{|l|c|c|}
\hline \multicolumn{1}{|c|}{ Variable } & $\begin{array}{c}\text { Univariate } \\
\text { OR (95\% CI) }\end{array}$ & $\begin{array}{c}\text { Multivariate } \\
\text { OR (95\% CI) }\end{array}$ \\
\hline Age & Reference & Reference \\
\hline $60-69$ years & $1.56(1.51-161)$ & $1.56(1.51-1.61)$ \\
\hline $70-79$ years & $2.46(2.36-2.58)$ & $2.49(2.38-2.61)$ \\
\hline $80-89$ years & $3.11(2.76-3.50)$ & $3.19(2.83-3.59)$ \\
\hline $90+$ years & $1.27(1.24-1.31)$ & $1.32(1.28-1.36)$ \\
\hline Sex & $1.05(1.00-1.11)$ & $0.97(0.92-1.03)$ \\
\hline Current smokers & $1.29(1.25-1.32)$ & $1.21(1.17-1.24)$ \\
\hline Hypertension & $1.18(1.12-1.24)$ & $1.13(1.07-1.19)$ \\
\hline Diabetes & $1.08(1.01-1.16)$ & $0.99(0.92-1.06)$ \\
\hline Dyslipidemia & $1.25(1.03-1.51)$ & $1.07(0.88-1.30)$ \\
\hline Chronic kidney disease & $2.52(2.32-2.75)$ & $2.56(2.35-2.80)$ \\
\hline Chagas disease & $1.16(1.01-1.33)$ & $0.98(0.85-1.12)$ \\
\hline COPD & $2.15(1.86-2.48)$ & $1.88(1.63-2.18)$ \\
\hline Previous MI & $1.16(1.12-1.21)$ & $1.05(1.01-1.09)$ \\
\hline Family historyof CAD & & \\
\hline
\end{tabular}

List of Abbrevations: CAD: Coronary Artery Disease; COPD: Chronic Obstructive Pulmonary Disease; MI: Myocardial Infarction

Table 2: Association between abnormal electrocardiogram and clinical characteristics

\begin{tabular}{|c|c|c|c|c|}
\hline $\begin{array}{l}\text { Electrocardiographic } \\
\text { abnormalities }\end{array}$ & $\begin{array}{l}\text { Prevalence }(\%) \\
\quad(\mathrm{N}=\mathbf{8 7}, \mathbf{8 0 4})\end{array}$ & $\begin{array}{l}\text { Patients with } \\
\text { hypertension } \\
(\mathrm{N}=42,752)\end{array}$ & $\begin{array}{l}\text { Patients without } \\
\text { hypertension } \\
(\mathrm{N}=45,052)\end{array}$ & p-value \\
\hline \multicolumn{5}{|c|}{ Rhythm } \\
\hline Atrial fibrillation & $3731(4.25)$ & $2008(4.70)$ & $1723(3.82)$ & $<0.001$ \\
\hline Pacemaker rhythm & $584(0.67)$ & $355(0.83)$ & $229(0.51)$ & $<0.001$ \\
\hline Ectopic atrial rhythm & $205(0.23)$ & $98(0.23)$ & $107(0.24)$ & 0.834 \\
\hline Junctional rhythm & $136(0.15)$ & $72(0.19)$ & $64(0.14)$ & 0.345 \\
\hline $\begin{array}{l}\text { Multifocal atrial } \\
\text { rhythm }\end{array}$ & $24(0.03)$ & $11(0.03)$ & $13(0.03)$ & 0.839 \\
\hline \multicolumn{5}{|c|}{ Intraventricular block } \\
\hline $\begin{array}{l}\text { Right bundle branch } \\
\text { block }\end{array}$ & $3921(4.47)$ & $2537(5.93)$ & $2282(5.07)$ & $<0.001$ \\
\hline $\begin{array}{l}\text { Left bundle branch } \\
\text { block }\end{array}$ & $3141(3.58)$ & $1560(3.65)$ & $1581(3.51)$ & 0.268 \\
\hline $\begin{array}{l}\text { Incomplete right bun- } \\
\text { dle branch block }\end{array}$ & $3121(3.55)$ & $1455(3.40)$ & $1666(3.70)$ & 0.019 \\
\hline $\begin{array}{l}\text { Incomplete left bundle } \\
\text { branch block }\end{array}$ & $2695(3.07)$ & $1070(2.50)$ & $1625(3.61)$ & $<0.001$ \\
\hline Left anterior hemiblock & $10260(11.69)$ & $5124(11.99)$ & $5136(11.40)$ & 0.007 \\
\hline $\begin{array}{l}\text { Left posterior hemi- } \\
\text { block }\end{array}$ & $259(0.29)$ & $137(0.32)$ & $122(0.27)$ & 0.191 \\
\hline \multicolumn{5}{|c|}{ Atrioventricular block } \\
\hline First degree & $3051(3.47)$ & $1557(3.64)$ & $1494(3.32)$ & 0.009 \\
\hline Second degree & $248(0.28)$ & $50(0.12)$ & $45(0.10)$ & 0.473 \\
\hline Third degree & $100(0.11)$ & $54(0.13)$ & $46(0.10)$ & 0.317 \\
\hline \multicolumn{5}{|c|}{ Hypertrophy/enlargement } \\
\hline $\begin{array}{l}\text { Left ventricular hyper- } \\
\text { trophy }\end{array}$ & $5468(6.23)$ & $2873(6.72)$ & $2595(5.76)$ & $<0.001$ \\
\hline Left atrial hypertrophy & $3921(4.47)$ & $1639(3.83)$ & $2282(5.07)$ & $<0.001$ \\
\hline $\begin{array}{l}\text { Right ventricular } \\
\text { enlargement }\end{array}$ & $99(0.11)$ & $47(0.11)$ & $52(0.12)$ & 0.841 \\
\hline
\end{tabular}




\begin{tabular}{|c|c|c|c|c|}
\hline $\begin{array}{l}\text { Electrocardiographic } \\
\text { abnormalities }\end{array}$ & $\begin{array}{l}\text { Prevalence }(\%) \\
\quad(\mathrm{N}=\mathbf{8 7}, \mathbf{8 0 4})\end{array}$ & $\begin{array}{c}\text { Patients with } \\
\text { hypertension } \\
(\mathrm{N}=42,752)\end{array}$ & $\begin{array}{l}\text { Patients without } \\
\text { hypertension } \\
(\mathrm{N}=45,052)\end{array}$ & p-value \\
\hline $\begin{array}{l}\text { Right atrial enlarge- } \\
\text { ment }\end{array}$ & $222(0.25)$ & $114(0.27)$ & $108(0.24)$ & 0.460 \\
\hline \multicolumn{5}{|c|}{ Ischemic } \\
\hline $\begin{array}{l}\text { Acute ischemic abnor- } \\
\text { malities (ST elevation } \\
\text { and ST depression) }\end{array}$ & $1604(1.83)$ & $778(1.82)$ & $826(1.83)$ & 0.903 \\
\hline $\begin{array}{l}\text { Poor R wave progres- } \\
\text { sion }\end{array}$ & $3656(4.16)$ & $1834(4.29)$ & $1822(4.04)$ & 0.071 \\
\hline Pathological Q waves & $1.509(1.80)$ & $796(1.86)$ & $783(1.74)$ & 0.170 \\
\hline \multicolumn{5}{|c|}{ Other } \\
\hline $\begin{array}{l}\text { Non-specific repolari- } \\
\text { zation abnormalities }\end{array}$ & $26712(30.42)$ & $14485(33.88)$ & $12227(27.14)$ & $<0.001$ \\
\hline $\begin{array}{l}\text { Premature supraven- } \\
\text { tricular beats }\end{array}$ & $4081(4.65)$ & $1601(3.74)$ & $1706(3.79)$ & 0.750 \\
\hline $\begin{array}{l}\text { Premature ventricular } \\
\text { beats }\end{array}$ & 3307 (3.77) & $1972(4.61)$ & $2109(4.68)$ & 0.630 \\
\hline Early repolarization & $398(0.45)$ & $169(0.40)$ & $229(0.51)$ & 0.014 \\
\hline
\end{tabular}

Table 3: Prevalence of electrocardiographic abnormalities stratified by hypertension

\section{Discussion}

The ECG is an important tool in the detection, prediction, and prevention of cardiac events on the primary care setting. This study, in a large database of elderly primary care patients, $48.7 \%$ of them with hypertension, showed that ECG abnormalities are common in this population: only $41.6 \%$ of the elderly had normal ECGs, significantly lower than younger patients, and this proportion decreased with ageing, reaching $23.3 \%$ in nonagenarians. Among patients who had abnormal ECG, it was frequent to have more than one abnormality.

The data was extracted from a one year population prevalence analysis in a region of Brazil, but it can be considered representative of the country. Minas Gerais is the Brazilian state with the largest number of cities (853) and the second in highest population, distributed in an area equivalent to France. Age and distribution and percentage of urbanization are similar to the overall national pattern, as well as are the social inequality. The north and the northeast of Minas Gerais have Human Development Index (HDI) similar to the North and Northeast Brazil, and while the west and the south of the state have HDI similar to the areas with the highest HDI of the country $[9,10]$.

Some authors point out that the limits between normality and pathology in the ECG of elderly patients are not well defined [11]. Aging is associated with extensive changes in cardiovascular structure and function which may result in ECG abnormalities [11,12]. The clinical significance of many of these abnormalities is uncertain. It is important to be clear for primary care physicians which abnormalities they have to continue propaedeutic or modify the patient treatment, and which ones have impact on prognosis, in order to avoid unnecessary referrals, interventions and costs.

Chagas disease (ChD) and previous myocardial infarction had stronger association with abnormal ECG. ChD is endemic in Latin American countries, with about eight to ten million infected subjects, and is a leading cause of cardiomyopathy [13,14]. Although the burden of the disease is falling, and $\mathrm{ChD}$ transmission is considered to be eliminated in Brazil. Due to a cohort effect, the disease is now a public health problem among older individuals [15]. As a consequence of immigration from endemic countries and international travel, it is now an emerging world health problem [14,16]. The common ECG abnormalities in ChD are right bundle-branch block (RBBB), often associated with left anterior hemiblock (LAH), and abnormalities of the conduction system, such as bradyarrhythmias and tachyarrhythmias [14]. In a previous analysis of the same database, Chagas disease was strongly associated with pacemaker rhythm (odds ratio [OR] 13.3 [95\% confidence interval 11.5-15.4]), RBBB (OR 10.7 [10.1-11.4]); RBBB associated with LAH (OR 12.1 [11.2-13.0]); and second (OR 4.0 [2.5-6.6]) and third degree (OR 4.1 [2.5-6.7] atrioventricular blocks. [17] Chagas disease might have overestimated the prevalence of those abnormalities in the present study.

Minor and major ECGs abnormalities are significantly associated with an increased risk of coronary heart disease, and they have been associated with improved risk prediction beyond traditional risk factors [18]. For example, LVH detected with standard ECG is a strong independent predictor of myocardial infarction, stroke, congestive heart failure and sudden cardiac death [19,20], and is associated with a poor prognosis in very old men and women [21]. Its prevalence is highly influenced by the criteria used [22]. In the present study, the prevalence of LVH criteria was similar to other studies, but slightly higher than the prevalence observed in the Bambuí cohort of elderly patients from Bambuí city, from the same province in Brazil, which ECGs were codified by the 
Minnesota code [23]. The prevalence of hypertension was similar in both studies. In the present study, LVH was more common in elderly with hypertension, as expected. This association of LVH with is usually explained by the response of the heart muscle to pressure overload [24].

Atrial fibrillation (AF) is associated with an increased risk of stroke, congestive heart failure, higher mortality and is an important cause of hospitalization [25]. This arrhythmia is a major cardiovascular challenge in modern society and its medical, social and economic aspects are all set to worsen over the coming decades [25]. The investigation of the prevalence of this cardiac rhythm disturbance is very relevant. The only study that assessed the prevalence of AF in elderly patients in Brazil showed a prevalence of $2.4 \%, 2.0 \%$ in women and $3.9 \%$ in men, smaller than what we observed. The sample size of that study was much smaller and comprehended patients of just one city, São Paulo [26]. We published a specific analysis of AF prevalence using the same database as the one used in this study, and showed that AF prevalence reached 8.4\% in octogenarians and $11.0 \%$ in nonagenarians [10]. In the present study, a stratified analysis that compared the prevalence of electrocardiographic abnormalities in the elderly with hypertension versus without hypertension showed a higher prevalence of AF in the first group, as expected. It is known that the prevalence of $\mathrm{AF}$ increases with age and also that hypertension is one of the risk factors for developing AF, as it can lead to cardiac dysfunction and electrical instability [27].

When comparing elderly with and without hypertension, it was observed that the abnormality with the largest difference between groups was the prevalence of nonspecific repolarization abnormalities, more common in patients with hypertension. There are few publications that analyzed the prevalence, prognosis and implications of nonspecific repolarization abnormalities in the elderly [24]. In the Cardiovascular Health Study the presence of those abnormalities were common in the elderly population and independently associated with increased risk for coronary heart disease mortality and with cardiac death, versus those without nonspecific repolarization abnormalities [28].

Smoking, dyslipidemia, chronic kidney disease and COPD were not independently associated with abnormal ECG in multivariate analysis. Smoking, dyslipidemia and chronic kidney disease are established cardiovascular risk factors, but they are not directly related to electrocardiographic abnormalities. Previous myocardial infarction was included in the model, and, as expected, it was significantly associated with abnormal ECG. COPD may be associated with ECG abnormalities [29]. However, the prevalence of self-reported COPD was low, so it may be an underdiagnosed condition in this population. The low prevalence might have impacted in the logistic regression results.

This study shows the importance of a telehealth service for the recognition of important conditions to health policies. Services like that helps with a second opinion of diagnoses, conducts and improves access to ECG reports that are not easy for most general practitioners. When the telehealth service is integrated to the health system, as in this case, the results of analysis of digital ECGs may have an important role in public health planning.

The study has some limitations. It included patients who sought primary care. Therefore, it may have overestimated the prevalence in the community. Comorbidities and medication data were self-reported, and thus might have been underreported. As this is a retrospective study, the data was extracted of the TNMG database, and some comorbidities are not included in the standardized questionnaire, for example, heart failure or alcohol abuse, and other variables were not extracted when the database was built, for example, cardiovascular medicines used.

\section{Conclusion}

This study, in a large sample of elderly individuals in primary care, extracted from a one year population prevalence analysis, showed that electrocardiographic abnormalities are common, with a prevalence which increases with ageing. ChD and previous MI were the variables with stronger association with abnormal ECG.

\section{Acknowledgment}

This study was supported by Fundação de Amparo a Pesquisa do Estado de Minas Gerais (FAPEMIG). The funder had no role in study design, data collection and analysis, decision to publish, or preparation of the manuscript.

\section{References}

1. Mendis S, Puska P, Norrving B (2011) Global Atlas on Cardiovascular Disease Prevention and Control. Geneva, Switzerland.

2. Mathers CD, Loncar D (2006) Projections of global mortality and burden of disease from 2002 to 2030. PLoS Med 3: e442.

3. Perk J, De Backer G, Gohlke H, Graham I, Reiner Z et al. (2012) European Guidelines on cardiovascular disease prevention in clinical practice (version 2012). Eur Heart J 33: 1635-701.

4. Molander U, Dey DK, Sundh V, Steen B (2003) ECG abnormalities in the elderly: prevalence, time and generation trends and association with mortality. Aging Clin Exp Res 15: 488-93.

5. Deldar K, Bahaadinbeigy K, Tara SM (2016) Teleconsultation and Clinical Decision Making: a Systematic Review. Acta Inform Med 24: 286-92.

6. Alkmim MB, Figueira RM, Marcolino MS, Cardoso CS, de Abreu MP, et al.(2012) Improving patient access to specialized health care: the Telehealth Network of Minas Gerais, Brazil. Bull World Health Org 90: 373-8. 
7. Sociedade Brasileira de Cardiologia (2009) Guidelines of Sociedade Brasileira de Cardiologia about analysis and issuance of expert opinion in electrocardiographic. Arq Bras Cardiol 93: 2-19.

8. Chugh SS, Havmoeller R, Narayanan K, Singh D, Rienstra M, et al. (2014) Worldwide epidemiology of atrial fibrillation: a Global Burden of Disease 2010 Study. Circulation 129: 837-47.

9. Atlas do Desenvolvimento Humano do Brasil (2013) Programa das Nações Unidas para o Desenvolvimento Instituto de Pesquisa Econômica Aplicada and Fundação João Pinheiro, Brazil.

10. Marcolino MS, Palhares DM, Benjamin EJ, Ribeiro AL (2015) Atrial fibrillation: prevalence in a large database of primary care patients in Brazil. Europace 17: 1787-90.

11. Molaschi M, Ponzetto M, Romin R, Berrino E, Fabris F (1995) Changes in the electrocardiogram in the elderly patient. The limits between normality and pathology. Recenti Prog Med. 86:32-6.

12. Basile G, Cucinotta MD, Figliomeni P, Lo Balbo C, Maltese G, et al. (2012) Electrocardiographic changes in centenarians: a study on 42 subjects and comparison with the literature. Gerontology 58: 216-20.

13. World Health Organization (2010) First WHO report on neglected tropical diseases: working to overcome the global impact of neglected tropical diseases, Geneva.

14. Schmunis GA, Yadon ZE (2010) Chagas disease: a Latin American health problem becoming a world health problem. Acta Tropica 115: 14-21.

15. Lima-Costa MF, Peixoto SV, Ribeiro AL (2010) Chagas disease and mortality in old age as an emerging issue: 10 year follow-up of the Bambui population-based cohort study (Brazil). Int J Cardiol 145: 362-63.

16. Nunes MC, Dones W, Morillo CA, Encina JJ, Ribeiro AL, et al. (2013) Chagas disease: an overview of clinical and epidemiological aspects. J Am Coll Cardiol 62: 767-76.

17. Marcolino MS, Palhares DM, Ferreira LR, Ribeiro AL (2015) Electrocardiogram and Chagas disease: a large population database of primary care patients. Glob Heart 10: 167-72.

18. Auer R, Bauer DC, Marques-Vidal P, Butler J, Min LJ, et al. (2012) Association of Major and Minor ECG Abnormalities With Coronary Heart Disease Events. JAMA 307: 1497-505.

19. Kannel WB, Cobb J (1992) Left ventricular hypertrophy and mortality-results from the Framingham Study. Cardiology 81: 291-8.

20. Bang CN, Soliman EZ, Simpson LM, Davis BR, Devereux RB, et al. (2017) Electrocardiographic Left Ventricular Hypertrophy Predicts Cardiovascular Morbidity and Mortality in Hypertensive Patients: The ALLHAT Study. Am J Hypertens 30: 914-22.

21. Kahn S, Frishman WH, Weissman S, Ooi WL, Aronson M, et al. (1996) Left ventricular hypertrophy on electrocardiogram: prognostic implications from a 10year cohort study of older subjects: a report from the Bronx Longitudinal Aging Study. J Am Geriatr Soc 44: 524-9.

22. Cuspidi C, Rescaldani M, Sala C, Negri F, Grassi G, et al. (2012) Prevalence of electrocardiographic left ventricular hypertrophy in human hypertension: an updated review. J Hypertens 30: 2066-73.

23. Ribeiro AL, Marcolino MS, Prineas RJ, Lima-Costa MF (2014) Electrocardiographic abnormalities in elderly Chagas disease patients: 10-year follow-up of the Bambui Cohort Study of Aging. J Am Heart Assoc. 3:e000632.

24. Sociedade Brasileira de Cardiologia / Sociedade Brasileira de Hipertensão / Sociedade Brasileira de Nefrologia (2010) VI Diretrizes Brasileiras de Hipertensão. Arq Bras Cardiol 95: 1-51.

25. January CT, Wann LS, Alpert JS, Calkins H, Cigarroa JE, et al. (2014) AHA/ACC/HRS Guideline for the Management of Patients With Atrial Fibrillation: A Report of the American College of Cardiology/American Heart Association Task Force on Practice Guidelines and the Heart Rhythm Society. J Am Coll Cardiol 64: $2246-80$.

26. Kawabata-Yoshihara LA, Bensenor IM, Kawabata VS, Menezes PR, Scazufca M, et al. (2009) Prevalence of electrocardiographic findings in elderly individuals: the Sao Paulo aging \& health study. Arq Bras Cardiol.93:602-7, 51-6.

27. Healey JS, Connolly SJ (2003) Atrial fibrillation : hypertension as a causative agent, risk factor for complications, and potential therapeutic target. Am J Cardiol 91: 9G-14G.

28. Kumar A, Prineas RJ, Arnold AM, Psaty BM, Furberg CD, et al. (2008) Prevalence, prognosis, and implications of isolated minor nonspecific ST-segment and T-wave abnormalities in older adults: Cardiovascular Health Study. Circulation 118: 2790-6.

29. Larssen MS, Steine K, Hilde JM, Skjørten I, Hodnesdal C, et al. (2017) Mechanisms of ECG signs in chronic obstructive pulmonary disease. Open Heart 4: e000552. 